\title{
Grazers structure the bacterial and algal diversity of aquatic metacommunities
}

\author{
Julia Birtel ${ }^{1,2}$ and Blake Matthews ${ }^{1,3}$ \\ ${ }^{1}$ Department of Aquatic Ecology, Eawag, Seestrasse 79, 6047 Kastanienbaum, Luzern, Switzerland \\ ${ }^{2}$ Department of Environmental Systems Sciences (D-USYS), Swiss Federal Institute of Technology (ETH), Zürich, Switzerland
}

\begin{abstract}
Consumers can have strong effects on the biotic and abiotic dynamics of spatiallystructured ecosystems. In metacommunities, dispersing consumers can alter local assembly dynamics either directly through trophic interactions or indirectly by modifying local environmental conditions. In aquatic systems, very little is known about how key grazers, such as Daphnia, structure the microbial diversity of metacommunities and influence bacterialmediated ecosystem functions. In an outdoor mesocosm experiment with replicate metacommunities (two $300 \mathrm{~L}$ mesocosms), we tested how the presence and absence of Daphnia and the initial density of the microbial community (manipulated via dilution) influenced the diversity and community structure of algae and bacteria, and several ecosystem properties (e.g., $\mathrm{pH}$, dissolved substances) and functions (e.g., enzyme activity, respiration). We found that Daphnia strongly affected the local and regional diversity of both phytoplankton and bacteria, the taxonomic composition of bacterial communities, the biomass of algae, and ecosystem metabolism (i.e., respiration). Diluting the microbial inoculum $(0.2-5 \mu \mathrm{m}$ size fraction) to the metacommunities increased local phytoplankton diversity, decreased bacteria beta-diversity, and changed the relative abundance of bacterial classes. Changes in the rank abundance of different bacterial groups exhibited phylogenetic signal, implying that closely related bacteria species might share similar responses to the presence of Daphnia.
\end{abstract}

Key words: bacteria; community assembly; consumers; Daphnia; metacommunities; phylogenetic diversity; phytoplankton.

\section{INTRODUCTION}

Consumers can profoundly modify community and ecosystem dynamics by affecting the biomass, composition, and diversity of their resources (Paine 1966, Duffy 2002, Schmitz et al. 2000), and by influencing nutrient cycling (Elser and Urabe 1999, McIntyre et al. 2008) and energy flux in ecosystems (Jones et al. 1997). The effects of consumers often extend well beyond their prey communities and can propagate both laterally and vertically throughout food webs (Duffy et al. 2007), influencing both the biomass (Shurin et al. 2002) and diversity of multiple trophic levels (Duffy 2002). The strong local effects of consumers on the composition and assembly of communities can also extend to influence the spatial structure of ecosystems (i.e., metacommunities and metaecosystems; Chase et al. 2009, Verreydt et al. 2012, Mouquet et al. 2013), likely through effects on colonization and extinction dynamics among communities (Chase 2003) and on fluxes of organic matter among ecosystem patches (Gravel et al. 2010).

The propagation of consumer effects throughout ecosystems can also indirectly control key ecosystem fluxes (Schmitz et al. 2014), including biogeochemical processes

Manuscript received 26 April 2016; revised 23 August 2016; accepted 19 September 2016. Corresponding Editor: Stuart Findlay.

${ }^{3}$ E-mail: blake.matthews@eawag.ch that are strongly mediated by bacteria (Ngai and Srivastava 2006, Falkowski et al.2008, Atwood et al.2013). In aquatic systems, for example, experimental manipulations of predators can significantly alter $\mathrm{CO}_{2}$ fluxes in ponds, streams, and bromeliads (Atwood et al. 2013). There is also mounting evidence that microbial diversity can influence ecosystem functioning (Battin et al. 2003, Bell et al.2005, Besemer et al. 2009, Comte and del Giorgio 2010), but little is known about the mechanisms by which consumers might alter the composition and diversity of microbial communities (Pernthaler 2005).

In aquatic systems, Daphnia is a useful model organism for exploring how consumers can affect ecosystems via their effects on the diversity of microbial communities at local (Jürgens 1994, Jürgens et al. 1994, Hahn and Hoefle 2001) and regional (Verreydt et al. 2012, Berga et al. 2014) scales. Daphnia is well known to affect both the abiotic and biotic environment of aquatic ecosystems, including water transparency (Mazumder and Lean 1994), nutrient cycling (Elser and Urabe 1999), atmospheric carbon exchange (Schindler 1997), and phytoplankton abundance, productivity, and diversity (Harvey et al. 1935, Sarnelle 2005). Such effects might be mediated by how Daphnia affects bacterial abundance, composition, and productivity (Jack and Gilbert 1994, Jürgens 1994, Jürgens et al. 1994, Hahn and Hoefle 2001, Langenheder and Jürgens 2001, Jürgens and Matz 2002, Zöllner et al. 2003, Sarnelle 2007, Berga et al. 2014), via 
a combination of both direct and indirect effects (Sterner 1986, Wickham 1998, Kamjunke and Zehrer 1999). For example, Daphnia can change the size distribution of bacteria directly by grazing (Kamjunke and Zehrer 1999), and indirectly by reducing small protists (e.g., $<10 \mu \mathrm{m}$ ) that are voracious bacterivores (Langenheder and Jürgens 2001, Sherr and Sherr 2002). The strong grazing effects of Daphnia on the abundance and diversity of phytoplankton (Sarnelle 2005), can also indirectly affect the availability of nutrients (Sterner 1986) and dissolved organic matter (Lampert 1978, Giraldo et al. 2007). Such indirect effects can either counteract or amplify the direct effects of Daphnia grazing on bacteria (Sterner 1986, Wickham 1998). At the regional scale (i.e., metacommunities and metaecosystems), there is experimental evidence that Daphnia can directly affect the diversity of both bacteria and phytoplankton (Verreydt et al. 2012, Berga et al. 2014). For example, Berga et al. (2014) found that Daphnia altered bacterial community composition (BCC) and respiration rates of microcosm metacommunities (1.5 L volumes), and Verreydt et al. (2012) found that Daphnia mediated the effects of dispersal on BCC (in $200 \mathrm{~L}$ mesocosms) through impacts on the abundance and composition of phytoplankton.

Several previous experiments have found strong effects of Daphnia on bacterial community composition (BCC) in aquatic systems (Jürgens 1994, Langenheder and Jürgens 2001, Zöllner et al. 2003, Declerck et al. 2012, Verreydt et al. 2012, Berga et al. 2014, Cram et al. 2016). However, it is difficult to generalize across these studies, because they varied widely in their duration (from a few days to months), were performed in vessels of different size $(<1-500 \mathrm{~L})$, and used a wide range of methods to quantify bacterial diversity (in situ hybridization, fingerprinting methods, next-generation sequencing). It is appealing to use NGS methods for quantifying BCC because they can (1) more finely resolve taxonomic groupings of common and rare microbial species, (2) help identify taxonomic groups that are known to have different functional traits, and (3) generate hypotheses about phylogenetic relationships among species (Birtel et al. 2015). Using NGS to quantify BCC in experiments has the underexploited advantage of being able to use a phylogenetic framework (Helmus et al. 2010) to test how consumers can influence community assembly processes (Vellend 2010) at both local and regional scales (Chase 2003, Fukami 2015).

Understanding how Daphnia influences the relative importance of stochastic and deterministic processes that govern the assembly of aquatic communities (Chase 2003, Chase et al. 2009, Hillebrand et al. 2009) might help us explain variation in the community and ecosystem effects of Daphnia. By manipulating the presence and absence of Daphnia in experimental metacommunities (Fig. 1A, B), we can test wether Daphnia decreases population densities of bacteria, potentially influencing the likelihood of local extinctions, particularly for rare species (Fig. 1D). Directly manipulating the starting density of bacteria, for example by diluting the inoculum to experimental ecosystems, could yield a similar effect (Fig. 1D). However, unlike a dilution manipulation that preferentially impacts rare species, the response of bacterial species to Daphnia might be more related to functional traits (e.g., grazing resistance, competitive ability) rather than abundance. In fact, previous studies have shown strong effects of Daphnia on bacteria composition independent of effects on biomass (Berga et al. 2014).

In general, consumers with strong local effects on species composition and abundance (e.g., Daphnia) can potentially simultaneously influence the stochastic and deterministic processes that govern community assembly (Chase et al. 2009). By using a factorial manipulation of Daphnia presence and a dilution of the innocula of the microbial community, we can experimentally test how Daphnia might temper the effect of stochastic processes and make the outcome of community assembly more or less deterministic (Chase et al. 2009). For example, Daphnia could reduce species richness locally via two processes: lowering bacterial biomass so as to increase the likelihood of stochastic extinction, and preferentially excluding species with certain traits (e.g., those vulnerable to grazing) that are independent of their initial abundance. Both of these processes could reduce local richness and increase the stochasticity of community assembly, leading to an increase of beta-diversity in a metacommunity. However, the latter process of preferentially removing species that are susceptible to grazing pressure could homogenize the regional pool of species and thereby increase the determinism of community composition, leading to a reduction of beta-diversity in the presence of Daphnia. A similar outcome would not be expected from the dilution treatment, unless grazing resistance traits were strongly correlated with relative abundance in the starting community. In light of such potential mechanisms and interactions, we predicted that Daphnia, but not dilution, could change the abundance of both dominant and rare species, possibly depending on their vulnerability to grazing and their competitive ability in ecosystems modified by Daphnia (Fig. 1D). Although we do not know a priori the distribution of species specific response to Daphnia grazing, we can estimate this from changes in the rank abundances of species and use it as a species-specific response trait to compare among treatments. Specifically, if the effects of Daphnia and dilution are similar across all species in our experiment, then we should expect no difference in the variance of rank abundance change among metacommunities (relative to a null model of rank abundance change), and no phylogenetic signal associated with these changes.

\section{Materials And Methods}

Experimental design and setup

We used a full-factorial $(2 \times 2)$ randomised block design (Fig. 1A) with 24 freshwater metacommunities 


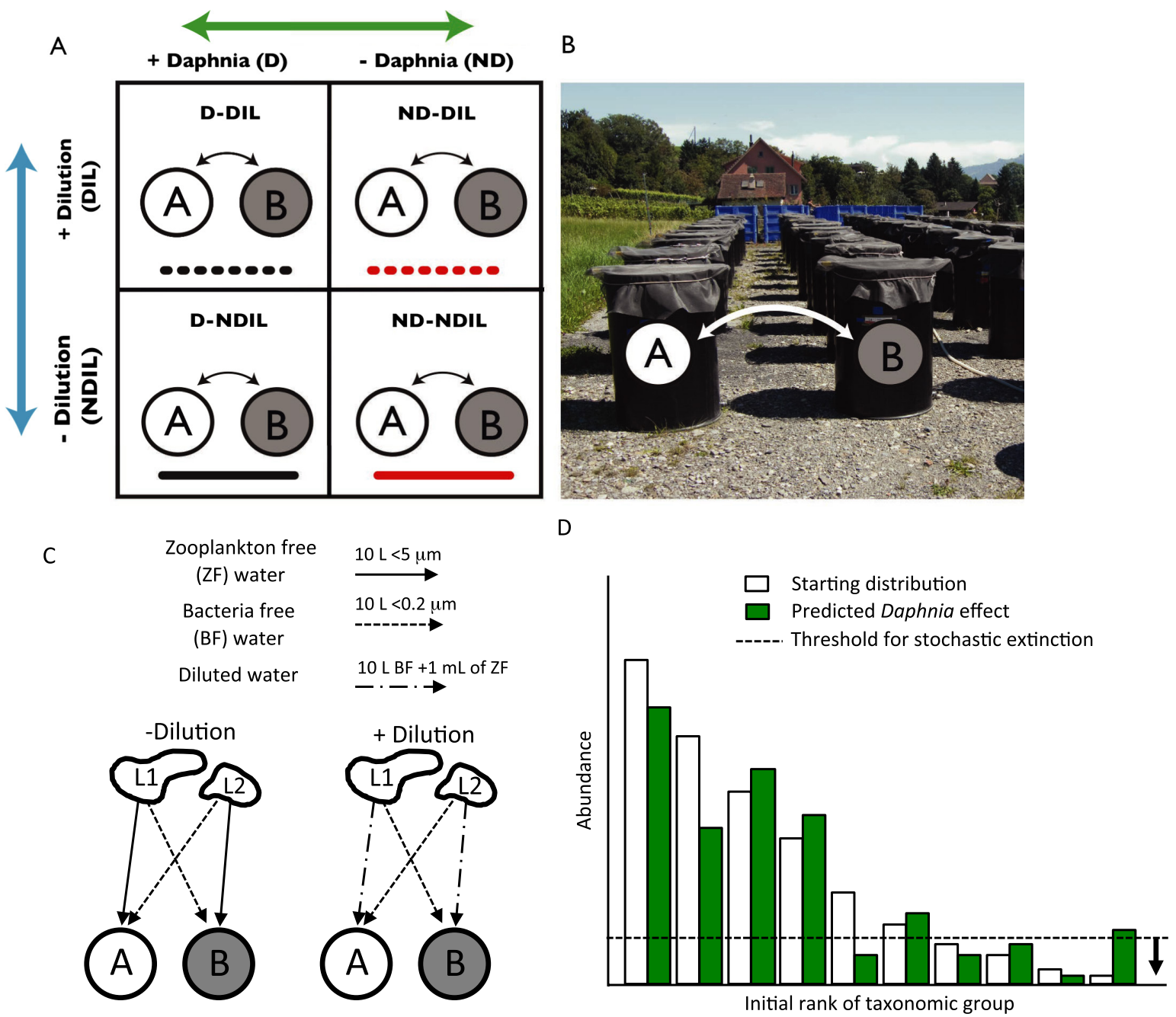

FIG. 1. Experimental design (A) and setting (B) of the mesocosm experiment, where each metacommunity is made up of two tanks (e.g., A and B) connected by manual dispersal. (C) Two lakes (i.e., L1 and L2) were used as the source water and propagules for each block of metacommunities. Undiluted metacommunities were inoculated with equal proportions of $\mathrm{ZF}$ and $\mathrm{BF}$ water, whereas diluted metacommunities were inoculated with equal proportions of BF water, and a small innocula of ZF water (1 mL). (D) We predicted that dilution would increase the chance of extinction for rare species (i.e., those below the dotted line), and change the relative proportion of bacteria compared to other community members (e.g., phytoplankton, protists, viruses). We predicted that Daphnia could both potentially either reduce or increase the abundance of both common and rare species. (Color figure can be viewed at wileyonlinelibrary.com.)

(i.e., six replicates of each block), each consisting of two $300 \mathrm{~L}$ mesocosms that were connected by weekly manual dispersal of $50 \mathrm{~mL}$ (Fig. 1). The four treatments were factorial combinations of two levels of Daphnia abundance (-Daphnia: 0 individuals; +Daphnia: 30 individuals) crossed with two levels of dilution (-Dilution; +Dilution: 1 million fold dilution of the bacteria innoculum).

Mesocosms were filled with approximately $250 \mathrm{~L}$ of unchlorinated tap water which originated from the nearby lake Lucerne. Each mesocosm received an equivalent inoculum of plankton from Lake Lucerne, that was concentrated within a size fraction $<100 \mu \mathrm{m}$ and $>10 \mu \mathrm{m}$. Each mesocosm of the + Daphnia treatment received 30 individuals of a single Daphnia galeata clone, which is a density that ensures all populations have a reasonable chance of becoming established. The clones were added with $100 \mathrm{~mL}$ of fresh culture water, and the -Daphnia treatments received the same amount of culture water but no Daphnia. We used Daphnia galeata (hereafter Daphnia) because it is known to graze bacteria sized particles, and can have both direct and indirect of effects on bacterial communities (Kamjunke and Zehrer 1999).

Each block (four treatment combinations), received lake water from a pair of two different lakes (six lake pairs, 12 lakes in total). These two lakes were paired randomly from a parallel lake survey of bacterial diversity (Birtel et al. 2015). In each metacommunity (i.e., two mesocosm), two types of filtered lake water were added to each mesocosm as an inoculum: Zooplankton free water $(\mathrm{ZF})$, which was prefiltered through $5 \mu \mathrm{m}$ filters to 
remove zooplankton and large phytoplankton, and Bacteria Free (BF), water which was ZF water additionally filtered through $0.2 \mu \mathrm{m}$ to remove bacteria. $\mathrm{ZF}$ water was used to seed each mesocosm with bacteria but each mesocosm only received $\mathrm{ZF}$ water from one lake (Fig. 1C). Because the amount of ZF water varied with the dilution treatment, we used BF from both lakes to ensure that all mesocosms received the same total volume of water, and to ensure similar starting environmental conditions (i.e., water composition, volume added). Specifically, undiluted mesocosms (- Dilution) received $10 \mathrm{~L}$ of $\mathrm{ZF}$ water from one of the lake, and $10 \mathrm{~L}$ of $\mathrm{BF}$ water from the other lake. Diluted (+ Dilution) mesocosm received $10 \mathrm{~L}$ of $\mathrm{BF}$ water and $1 \mathrm{~mL}$ of $\mathrm{ZF}$ water from the same lake, as well as $10 \mathrm{~L}$ of BF water from the other lake in the pair of lakes used for each block. We chose to dilute the bacterial community by a factor of one million in order to remove rare species and to dramatically suppress initial densities of bacteria relative to other species in the mesocosm (Fig. 1D). The mesocosm experiment ran for 12 weeks in 2011 (Aug to Oct).

\section{Mesocosm sampling and analyses}

Over the course of the experiment, we measured various biological, physical, chemical, and ecosystem functions on a regular basis (Appendix S1: Table S1). We performed weekly samplings of algal biomass (Chlorophyll a), dissolved organic carbon (DOC) concentration and DOC composition, as well as bacterial cell densities and cell size distribution. At the end of the experiment, we measured a larger suite of ecosystem metrics, including physical-chemical metrics (e.g., pH, oxygen, conductivity, temperature, and light extinction), and ecosystem functions (e.g., phosphatase activity, respiration rates; Appendix S1: Table S1).

To measure algal biomass, we filtered between 500 $1000 \mathrm{~mL}$ of water through $47 \mathrm{~mm}$ ashed GF/Fs (6 h at $450^{\circ} \mathrm{C}$ ), and extracted Chlorophyll-a by immersing filters in $8 \mathrm{~mL}$ of $90 \%$ ethanol, sonicating the vials in a $78^{\circ} \mathrm{C}$ water bath (10 min), and measuring absorption at $665 \mathrm{~nm}$ using a Hitachi U 2000 spectrophotometer. The filtrate was acidified and stored at $4^{\circ} \mathrm{C}$ for measuring DOC concentration on a Shimadzu TOC-V CPH, and DOC absorption spectrum over the wavelengths of 190-800 nm on a Hitachi U 2000 spectrophotometer. We used flow cytometry to measure bacteria cell density and size (Prest et al. 2013). Specifically, we fixed $40 \mathrm{~mL}$ of tank water with a filter-sterilized solution of paraformaldehyde and glutaraldehyde $(0.01 \%$ and $0.1 \%$ final concentrations, $\mathrm{pH}$ 7; Nizzetto et al. 2012) and stored samples at $4^{\circ} \mathrm{C}$ until flow cytometric measurements were carried out on a BD Accuri $^{\text {TM }}$ C6 Flowcytometer (Prest et al. 2013).

Phytoplankton was sampled from the water column (100 mL), preserved with Lugol's solution, and analyzed using inverted microscopy (Pomati et al. 2013). Dissolved oxygen, $\mathrm{pH}$, temperature and conductivity were measured in situ at approximately $0.5 \mathrm{~m}$ water depth using portable water sensors. We used respiration rates and phosphatase enzyme activity as two metrics of ecosystem functioning. We measured respiration rates in the lab using a custombuilt temperature controlled incubator $\left(16^{\circ} \mathrm{C}\right)$ and fiberoptic oxygen mini-sensors(FIBOX 3, PreSens). Respiration rate was measured as the rate of oxygen decline over $6 \mathrm{~h}$, with measurements taken every $30 \mathrm{~s}$. In general, enzyme activities are useful indicators of the level of microbial activity associated with specific biogeochemical processes (Sinsabaugh et al. 2008). Phosphatase activity is specifically associated with the mineralizing $\mathrm{P}$ from organic matter, and was quantified following German et al. (2011). For our experiment, phosphatase activity provided an ecosystem function that was more specific to bacterial activity, and commonly used to investigate relationships between community structure and function (Frossard et al. 2011).

The bacterial community was analyzed using Illumina sequencing (Birtel et al. 2015). Briefly, mesocosm water was filtered onto $0.2 \mu \mathrm{m}$ polyethersulfone filters (Supor 200 Membrane Disc Filters), which were instantly frozen in liquid nitrogen and preserved at $-80^{\circ} \mathrm{C}$ until further processing. DNA was extracted by enzymatic digestion and cetyltrimethyl ammonium bromide (CTAB) extraction using a modified protocol of Llirós et al. (2008). Ilumina sequencing and sequence analysis were performed as described previously (Birtel et al. 2015), and here we used the $\mathrm{V} 3$ region of the $16 \mathrm{~S}$ rRNA for the analysis of bacterial diversity.

\section{Data analysis}

Profile analysis of the time-series data was performed for bacterial abundance, bacterial size distribution, and chlorophyll concentrations. Profile analysis is an alternative to repeated-measures ANOVA (RM-ANOVA) with less restrictive assumptions (Fidell and Tabachnick 2006). It has three analogous tests to RM-ANOVA: flatness test, which tests wether the change over time (e.g., Time effect in RM-ANOVA), levels test, which tests wether average values of the profiles differ (e.g., Treatment effect in RM-ANOVA), and parallelism test, which tests whether profiles are parallel or not(e.g., a Time*Treatment effect in RM-ANOVA). Profile analysis was conducted on each of the treatment combinations, as well as for the Daphnia and the dilution contrast.

Illumina sequences were analyzed using the bioinformatics pipeline QIIME (Kuczynski et al. 2011, Birtel et al. 2015), and diversity was analysed using linear mixed effect models in R (R Development Core Team, 2014). In almost all cases (except for some of the phylogenetic analyses), samples were rarefied to 200 reads per mesocosm prior to analysis (Birtel et al. 2015).

Estimates of $\alpha, \beta$ and $\gamma$-diversity, as well as phylogenetic diversity and dissimilarity were computed for each bacterial metacommunity based on the average of 1,000 rarefactions, each of 200 reads. Although our low number of reads likely underestimates alpha diversity (Lundin et al. 2012), our method provides a robust index of diversity for 
comparing among our experimental treatments (Birtel et al. 2015). In our study, species richness (SR; $\alpha$-diversity $=$ local diversity) was calculated as the number of unique OTUs (or phytoplankton species) per tank and then averaged across metacommunities. $\beta$-diversity was estimated for each metacommunity using Jaccard and BrayCurtis dissimilarities, and $\gamma$-diversity was calculated as the total number of unique OTUs per metacommunity. Bacterial phylogenetic diversity (PD) was quantified as the sum of phylogenetic branch length (Cadotte et al. 2008), and phylogenetic dissimilarity was calculated using UniFrac distances (Lozupone and Knight 2005).

In order to test for treatment effects on the rank abundance distribution of bacteria (Fig. 1D), we rarified our data for each mesocosm sample to 200 reads (noted previously for the diversity analyses), and then we selected the 300 most abundant OTUs over the entire experiment for further analyses. For each metacommunity, we calculated (1) rank abundance slopes, (2) average ranks for each OTU, and (3) changes in the ranks of each OTU between treatment combinations. We then tested for phylogenetic signal of each OTU's change in rank using Blomberg's K. To test for significant phylogenetic signal, we repeated this analysis 100 times between treatment combinations, and calculated the proportion of significant $P$-values $(P<0.05)$. In order to visualize these results, we aggregated the phylogenetic tree to the class level, and for each tip of the tree we calculated class level averages (i.e., for multiple OTUs) of both relative abundance and change in rank.

\section{RESULTS \\ Ecosystem dynamics through time}

Over the course of the experiment, we found significant effects of both dilution and Daphnia addition on the dynamics of bacterial abundance, bacterial size distribution, and algal biomass (Table 1, Fig. 2). On certain sampling dates, we found either effects of Daphnia, dilution, or their interaction (Fig. 2A-C). For example, Daphnia lowered bacteria density on week 6 (Fig. 2A), increased bacteria cell size on weeks 4 and 6 (Fig. 2B), and decreased algal biomass on nearly all sampling dates (Levels test; Table 1, Fig. 2C). Dilution had weaker overall effects on ecosystem dynamics than Daphnia but did have interactive effects with Daphnia on algal biomass (weeks 3, 6, 9) and bacterial density (week 2).

On the last sampling day of the experiment (week 12), metacommunities with Daphnia had a lower density and biomass of phytoplankton, but there was no difference in the abundance or size of bacteria (Table 1). Dilution had no effect on the biomass and abundance of both bacteria and phytoplankton (Table 2). In our analysis of ecosystem functioning, we found no treatment effects on phosphatase activity but an interactive effect on respiration rate (Table 2, Appendix S1: Figure S2).

\section{Treatment effects on biodiversity}

We found that Daphnia decreased both the local $(\alpha)$ and regional $(\gamma)$ diversity of phytoplankton (Fig. 3), but this did not affect $\beta$-diversity. Diluting the initial inocula increased $\alpha$ diversity of phytoplankton (Fig. 3), but had no effects on $\beta$-diversity (Table 2). Daphnia also significantly reduced local $(\alpha)$ and regional $(\gamma)$ diversity of the bacteria community, and, similar to the phytoplankton, had no effect on the community similarity (i.e., $\beta$ ) among metacommunity sites (Fig. 3, Table 2). Although Daphnia did not significantly alter the $\beta$-diversity of either phytoplankton or bacteria, diluting the initial inocula caused the bacterial communities within a metacommunity to be more similar (Table 2: Dilution effect on $\beta$-diversity). The combined effects of dilution and Daphnia were particularly evident when comparing the composition of the ten most abundant classes of the bacterial community, which together represented approximately $82 \%$ of all OTUs (Fig. 4, Table 2). For example, we found an interactive effect of Daphnia and dilution on Betaproteobacteria, which was the most abundant class of bacteria, comprising almost $40 \%$ of all OTUs. We also found that Daphnia caused an increase in relative abundance of Alphaproteobacteria, whereas dilution caused a decrease in the relative abundance of Saprospirae and Flavobacteria (Table 2).

Overall, Daphnia had strong effects on both bacterial community composition (Fig. 4) and phylogenetic

TABLE 1. Results of profile analysis on bacterial abundance (BaN), bacterial size class distribution (BactSize) and Chlorophyll a (Chl-a).

\begin{tabular}{lccccc}
\hline \hline Test & Comparison & Test statistic & BaN & BactSize & Chl-a \\
\hline Time (Flatness) & Treatment & $F_{10,11}$ & $\mathbf{6 . 2 9}(<\mathbf{0 . 0 1})$ & $\mathbf{8 . 5 8}(<\mathbf{0 . 0 1})$ & $\mathbf{1 0 . 0 3}(<\mathbf{0 . 0 1})$ \\
& Daphnia & $F_{12,11}$ & $\mathbf{6 . 0 7}(<\mathbf{0 . 0 1})$ & $\mathbf{8 . 7 3}(<\mathbf{0 . 0 1})$ & $\mathbf{7 . 9 9}(<\mathbf{0 . 0 1})$ \\
& Dilution & $F_{12,11}$ & $\mathbf{7 . 0 8}(<\mathbf{0 . 0 1})$ & $\mathbf{6 . 8 2}(<\mathbf{0 . 0 1})$ & $\mathbf{7 . 3 7}(<\mathbf{0 . 0 1})$ \\
Treatment (Levels) & Treatment & $F_{3,20}$ & $1.37(0.28)$ & $0.77(0.53)$ & $\mathbf{9 . 4 2}(<\mathbf{0 . 0 1})$ \\
& Daphnia & $F_{1,22}$ & $0.81(0.38)$ & $2.48(0.13)$ & $\mathbf{1 8 . 7 6}(<\mathbf{0 . 0 1})$ \\
Time $\times$ Treatment (Parallelism) & Dilution & $F_{1,22}$ & $0.00(0.99)$ & $0.01(0.92)$ & $0.69(0.41)$ \\
& Treatment & Wilk's $\lambda_{3,20}$ & $\mathbf{0 . 0 4}(\mathbf{0 . 0 5})$ & $\mathbf{0 . 0 3}(\mathbf{0 . 0 2})$ & $0.07(0.23)$ \\
& Daphnia & Wilk's $\lambda_{1,22}$ & $\mathbf{0 . 2 7}(\mathbf{0 . 0 4})$ & $\mathbf{0 . 1 7}(<\mathbf{0 . 0 1})$ & $0.41(0.23)$ \\
& Dilution & Wilk's $\lambda_{1,22}$ & $0.33(0.10)$ & $0.35(0.13)$ & $0.40(0.20)$ \\
\hline
\end{tabular}



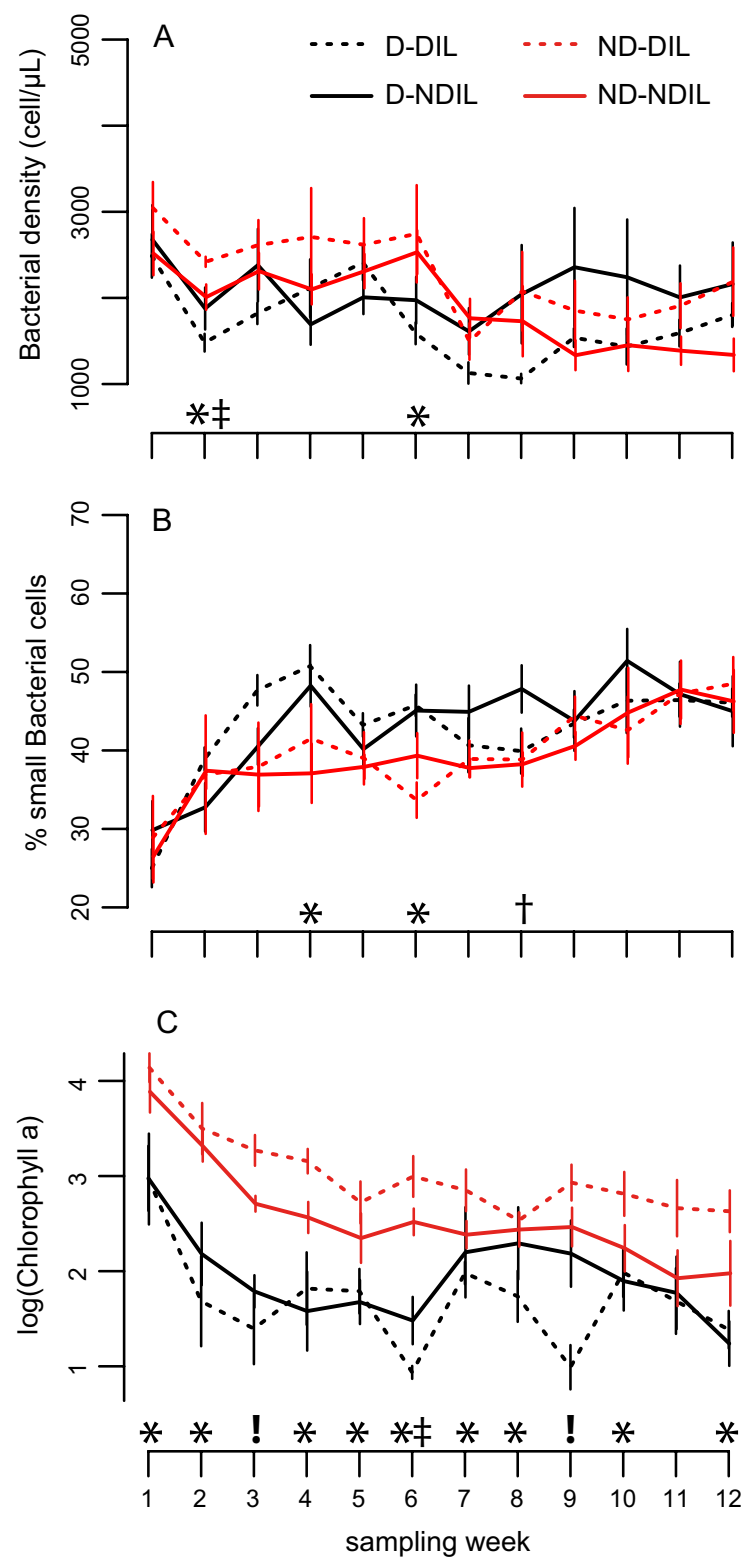

FIG. 2. Time series plot of bacterial density (A), proportion of small bacterial cells (B) and chlorophyll a (C). Symbols indicate significant result of linear mixed effect model for the 12 weeks of the experiment. *: significant effect of Daphnia treatment; $\uparrow$ : significant effect of Dilution treatment; $\$$ : significant interaction; !: Daphnia, Dilution and Interaction significant. (Color figure can be viewed at wileyonlinelibrary.com.)

diversity (PD: Appendix S1: Figure S1). The average metacommunity PD (Appendix S1: Figure S1A) was significantly lower in the presence of Daphnia $(P<0.01)$, and was unaffected by dilution $(P=0.21)$. Metacommunities with and without Daphnia did not differ in their phylogenetic dissimilarity (Appendix S1: Figure S1B, unweighted UniFrac: $P=0.72$ ).

The bacterial rank-abundance distributions, which are a combined measure of species richness and evenness, differed among treatments (Table 2). While our dilution treatment had no effect on rank-abundance slopes, we found steeper slopes for metacommunities with Daphnia (Fig. 5A+B, Table 2). In the absence of Daphnia, there were more species present and a shallower rankabundance slope. We also found that the variance in rank changes of individual OTUs between Daphnia presenceabsence treatments was larger than between the dilution treatments (Fig. 5C+D). Interestingly, the rank changes between Daphnia treatments showed strong phylogenetic signal (Appendix S1: Table S3), indicating that closely related species have more similar responses to Daphnia than expected by chance (Fig. 6).

\section{DisCUSSION}

Our results show that both bacterial and phytoplankton communities are strongly affected by the presence of Daphnia, and to a lesser extent, by altering the starting community of bacteria via dilution (Table 2). Our experiment was partly motivated by the previous study by Chase et al. (2009), which found that fish predation reduced the diversity of macroinvertebrates, zooplankton and amphibians at both local $(\alpha)$ and regional $(\gamma)$ scales, and increased community similarity (lower $\beta$-diversity). Chase et al. (2009) suggested that plankton communities became more similar in the presence of fish because a smaller subset of species within the regional pool shared the traits necessary to coexist with fish predators (e.g., small body size, avoidance behaviors), and concluded that deterministic processes become more important for community assembly in the presence of a fish predator Chase et al. (2009). In our study, we focused on how Daphnia grazing, combined with a manipulation of the initial community of bacteria, affects the community assembly of both bacteria and phytoplankton communities. Similar to the results from Chase et al. (2009), we also found a significant decrease in $\alpha$ - and $\gamma$-diversity of both the bacterial and the phytoplankton community in the presence of Daphnia (Fig. 3). In addition, we found strong effects of Daphnia on species composition and phylogenetic diversity of metacommunities. However, in contrast to the results from Chase et al. (2009), we found no evidence that Daphnia affected the $\beta$-diversity of either the bacterial or the phytoplankton community, meaning that communities did not become more similar to each other in the presence of Daphnia.

The diversity of both bacterial and phytoplankton communities decreased in the presence of Daphnia, but these patterns likely arose from very different mechanisms. Daphnia are relatively nonselective filter feeders (Hartmann and Kunkel 1991), and their ingestion of phytoplankton by Daphnia depends on the mesh size of their filtration apparatus (Gophen and Geller 1984) and on the palatability of the phytoplankton species (Böing et al. 1998). Over the course of the 12 -week experiment, algal biomass declined in the presence of Daphnia (Fig. 2C) and this strong grazing pressure was probably 

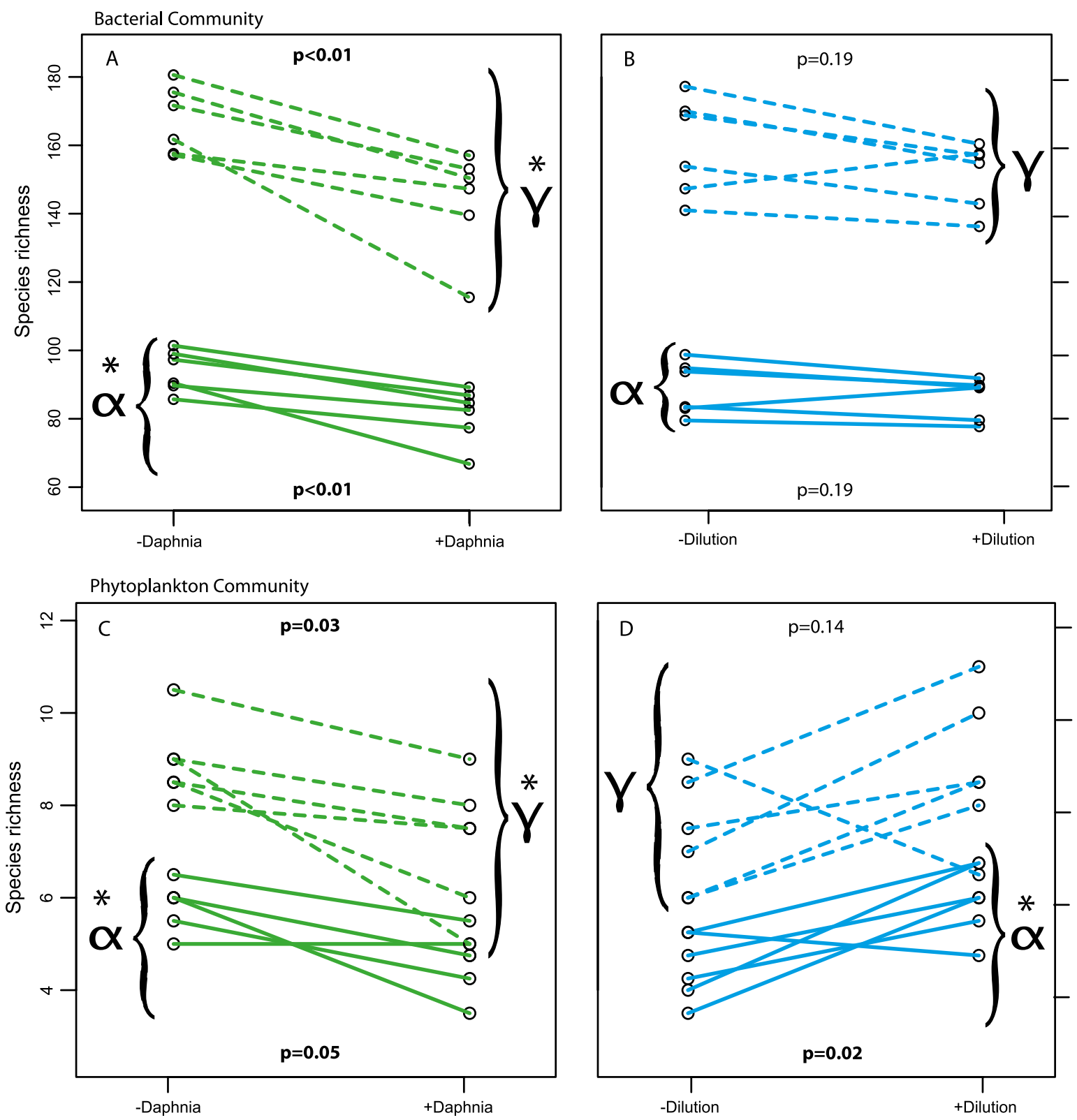

FIG. 3. Diversity results for bacterial (A, B) and phytoplankton community (C, D). Changes in $\alpha$ and $\gamma$-diversity as an effect of Daphnia and Dilution treatment. Each dot represents block average. Colors indicate treatment contrast (see Fig. 1). Solid lines: $\alpha$-diversity, dashed lines: $\gamma$-diversity. $P$-values indicate significance as determined by linear mixed effect model (Table 1). (Color figure can be viewed at wileyonlinelibrary.com.)

responsible for the reductions in $\alpha$ - and $\gamma$-diversity of phytoplankton, possibly driven by more stochastic extinctions occurring at low cell densities. We are unsure how such effects of Daphnia on phytoplankton abundance and diversity might indirectly influence bacteria diversity, and recommend that future studies design experiments that disentangle the direct and indirect effects of consumers on the diversity of interacting communities at lower trophic levels. Our dilution manipulation caused an increase in $\alpha$ - and $\gamma$-diversity of the phytoplankton community, and a decrease in $\beta$-diversity.
The decline in $\beta$-diversity might suggest that deterministic processes are important drivers of phytoplankton community composition when the initial abundance of bacterial and small phytoplankton cells is reduced (i.e., in the size fraction $0.2-5 \mu \mathrm{m}$ ). It is possible that our dilution manipulation altered competitive interactions between species in the size fraction $0.2-5 \mu \mathrm{m}$ and larger algal species in the original phytoplankton inoculum (size range: $>10 \mu \mathrm{m}$ and $<100 \mu \mathrm{m}$ ). However, other mechanisms involving dilution effects are also possible, including changes in encounter rates between species 
TABLE 2. Summary of ANOVA results from the last sampling (week 12) of the metacommunity experiment. $F$ and $P$ results for the effect of Daphnia, dilution, and interactive effects. Significant values are highlighted wild bold letters.

\begin{tabular}{|c|c|c|c|c|}
\hline \multirow[b]{2}{*}{ Metrics } & \multirow[b]{2}{*}{ Parameter } & \multicolumn{3}{|c|}{$F$ and $P$ values of ANOVA analysis } \\
\hline & & Daphnia & Dilution & Interaction \\
\hline \multirow[t]{12}{*}{ Bacterial community } & $\alpha$-diversity (Species richness) & $14.80(<0.01)$ & $1.90(0.19)$ & $1.02(0.33)$ \\
\hline & $\beta$-diversity (Jaccard) & $1.23(0.28)$ & $5.70(0.03)$ & $0.24(0.63)$ \\
\hline & $\beta$-diversity (Bray-Curtis) & $3.77(0.07)$ & $4.43(0.05)$ & $0.21(0.66)$ \\
\hline & $\beta$-diversity (Raup-Crick - Presence-Absence) & $0.06(0.81)$ & $0.66(0.43)$ & $2.12(0.17)$ \\
\hline & $\beta$-diversity (Raup-Crick - Abundance) & $0.47(0.50)$ & $0.56(0.47)$ & $0.15(0.70)$ \\
\hline & $\gamma$-diversity & $13.59(<0.01)$ & $1.90(0.19)$ & $1.02(0.33)$ \\
\hline & Phylogenetic Diversity & $13.08(<0.01)$ & $1.74(0.21)$ & $0.57(0.46)$ \\
\hline & Rank abundance slopes (log-log) & $10.44(0.01)$ & $1.80(0.20)$ & $0.21(0.66)$ \\
\hline & UniFrac distance & $0.14(0.72)$ & $3.43(0.08)$ & $0.04(0.85)$ \\
\hline & Weighted UniFrac distance & $0.12(0.73)$ & $2.33(0.15)$ & $0.00(0.95)$ \\
\hline & Bacterial density & $0.72(0.41)$ & $0.62(0.44)$ & $3.51(0.08)$ \\
\hline & Bacterial size & $0.28(0.60)$ & $0.06(0.82)$ & $0.03(0.86)$ \\
\hline \multirow[t]{11}{*}{ Top 10 bacterial classes } & Betaproteobacteria $(39 \%)$ & $30.67(<0.01)$ & $14.17(<0.01)$ & $16.94(<0.01)$ \\
\hline & Alphaproteobacteria $(11 \%)$ & $18.79(<0.01)$ & $0.47(0.50)$ & $1.04(0.32)$ \\
\hline & Saprospirae (Bacteriodetes) $(8 \%)$ & $1.55(0.23)$ & $4.90(0.04)$ & $0.35(0.56)$ \\
\hline & Flavobacteriia $(6 \%)$ & $1.26(0.28)$ & $8.29(0.01)$ & $3.04(0.10)$ \\
\hline & Cytophagia $(5 \%)$ & $3.59(0.08)$ & $0.14(0.71)$ & $0.07(0.80)$ \\
\hline & Gammaproteobacteria (5\%) & $0.72(0.41)$ & $0.09(0.77)$ & $0.04(0.85)$ \\
\hline & Chloroplasts (Cyanobacteria) $(2 \%)$ & $2.35(0.15)$ & $4.93(0.04)$ & $0.83(0.38)$ \\
\hline & Sphingobacteriia $(2 \%)$ & $0.58(0.46)$ & $1.74(0.21)$ & $2.16(0.16)$ \\
\hline & Verrucomicrobiae $(2 \%)$ & $3.44(0.08)$ & $0.02(0.89)$ & $2.42(0.14)$ \\
\hline & Actinobacteria $(2 \%)$ & $18.25(<0.01)$ & $1.36(0.26)$ & $1.72(0.21)$ \\
\hline & Others $(18 \%)$ & $18.73(<0.01)$ & $2.56(0.13)$ & $2.70(0.12)$ \\
\hline \multirow[t]{10}{*}{ Phytoplankton community } & $\alpha$-diversity (Species richness) & $5.53(0.03)$ & $7.10(0.02)$ & $0.01(0.91)$ \\
\hline & $\beta$-diversity (Jaccard) & $0.09(0.77)$ & $3.42(0.08)$ & $0.11(0.75)$ \\
\hline & $\beta$-diversity (Bray-Curtis) & $0.00(0.99)$ & $0.12(0.74)$ & $0.16(0.69)$ \\
\hline & $\beta$-diversity (Raup-Crick - Presence-Absence) & $0.42(0.52)$ & $0.65(0.43)$ & $0.03(0.87)$ \\
\hline & $\beta$-diversity (Raup-Crick - Abundance) & $0.31(0.59)$ & $0.18(0.68)$ & $0.37(0.55)$ \\
\hline & $\gamma$-diversity & $4.61(0.05)$ & $2.44(0.14)$ & $0.02(0.89)$ \\
\hline & Rank abundance slopes (log-log) & $1.71(0.21)$ & $0.40(0.54)$ & $1.89(0.19)$ \\
\hline & Phytoplankton density (FCM) & $6.49(0.02)$ & $0.02(0.89)$ & $0.40(0.54)$ \\
\hline & Phytoplankton counts & $10.37(0.01)$ & $0.09(0.77)$ & $1.45(0.25)$ \\
\hline & Chlorophyll-a & $10.43(0.01)$ & $0.02(0.89)$ & $1.41(0.25)$ \\
\hline \multirow[t]{7}{*}{ Physical/chemical } & DOC & $0.05(0.82)$ & $0.21(0.65)$ & $0.13(0.73)$ \\
\hline & DOC Spectral slope & $2.91(0.11)$ & $0.07(0.79)$ & $0.04(0.85)$ \\
\hline & DOC Absorption a 320 & $1.06(0.32)$ & $0.41(0.53)$ & $0.06(0.81)$ \\
\hline & Dissolved oxygen & $9.40(0.01)$ & $0.57(0.46)$ & $0.89(0.36)$ \\
\hline & $\mathrm{pH}$ & $3.98(0.06)$ & $0.25(0.62)$ & $0.13(0.73)$ \\
\hline & Temperature & $3.56(0.08)$ & $1.47(0.24)$ & $3.28(0.09)$ \\
\hline & Conductivity & $0.85(0.37)$ & $0.63(0.44)$ & $0.36(0.56)$ \\
\hline \multirow[t]{2}{*}{ Ecosystem functions } & Enzyme (phosphatase) activity & $1.36(0.26)$ & $0.16(0.70)$ & $0.00(0.99)$ \\
\hline & Respiration & $10.73(0.01)$ & $2.82(0.11)$ & $6.01(0.03)$ \\
\hline
\end{tabular}

(Cram et al. 2016) and rates of colonization via areal dispersal (Jones et al. 2008).

Compared to the well studied effects of Daphnia on phytoplankton (Harvey et al. 1935, Sarnelle 2005), much less is known about how Daphnia might influence the abundance and diversity of bacterial communities (Berga et al. 2014). In our experiment, bacterial cell densities remained fairly constant throughout the experiment (Fig. 2A), suggesting either weak top down grazing pressure by Daphnia or rapid compensation by grazing resistant species. Previous research has shown strong effects of Daphnia grazing on bacterial communities (Kamjunke and Zehrer 1999, Jürgens and Matz 2002, Berga et al. 2014). For example, Jürgens and Matz (2002) found that small bacterial cells dominate in the presence of Daphnia due to reduced densities of phagotrophic protists that feed on bacteria, such as heterotrophic nanoflagellates (HNF) and ciliates. Daphnia galeata can feed directly on large bacterial cells and this could alter size structure of bacteria independent of effects on abundance 
A

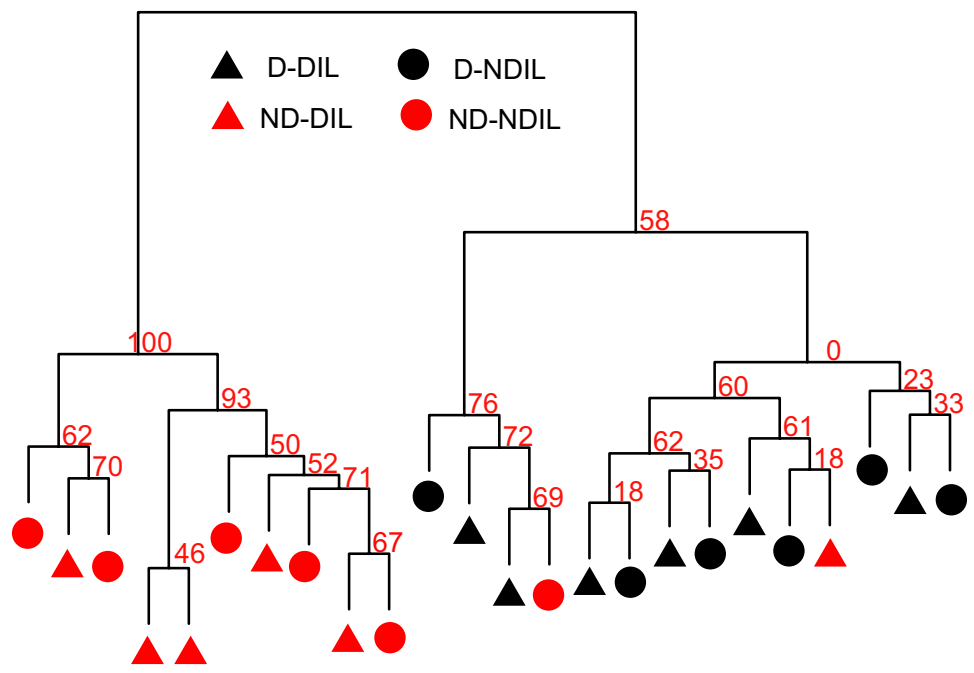

B

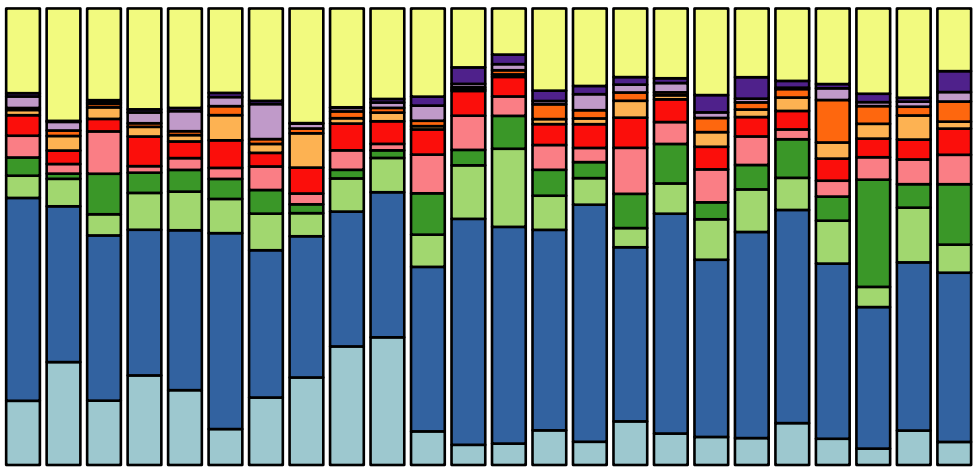

\section{Legend}

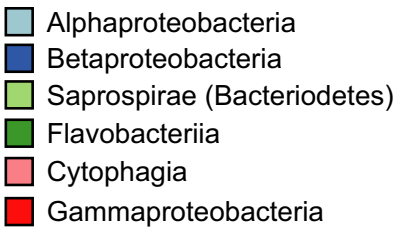

\author{
Chloroplasts (Cyanobacteria) \\ Sphingobacteriia \\ Verrucomicrobiae \\ Actinobacteria \\ Others
}

FIG. 4. Hierarchical clustering of UniFrac distances of the 24 metacommunities (Top) as well as bacterial composition of the corresponding metacommunities for the 10 most abundant classes. Colors and symbols of the top part indicate the 4 different treatments (see Fig. 1), red numbers: AU (approximately unbiased) $P$-values. (Color figure can be viewed at wileyonlinelibrary.com.)

(Kamjunke and Zehrer 1999). Indeed, in our experiment we found smaller bacterial cells in metacommunities with Daphnia (Fig. 2B) despite no differences in total cell concentration. We also found that Daphnia reduced the $\alpha$ and $\gamma$-richness and phylogenetic diversity (Fig. 3; Appendix S1: Figure S2), altered the composition of the entire community (Fig. 4), and changed the abundance of dominant bacteria classes (e.g., Alphaproteobacteria, Betaproteobacteria and Actinobacteria). Changes in bacterial community composition might be due to the direct effects of Daphnia grazing on size and species composition (Kamjunke and Zehrer 1999, Jürgens and Matz 2002), or due to a wide range of indirect trophic (e.g., Daphnia grazing effects on bacteriovores) and nontrophic effects (e.g., effects of Daphnia on nutrient recycling) on bacterial communities (Pernthaler 2005). For example, Alphaproteobacteria were more abundant in the absence of Daphnia during our study, and species of this class are known to form filaments to resist ingestion by heterotrophic nanoflagellates (Jürgens et al. 1999), which often decrease in the presence of Daphnia. Betaproteobacteria are also known to be sensitive to HNF grazing (Salcher et al. 2010), and in our experiment they increased in relative abundance when Daphnia was present. Regardless of the specific mechanisms, our results demonstrate that Daphnia can be a strong structuring force on the community composition of bacteria.

A novel result from our study is that Daphnia can strongly affect the rank abundance distribution of the community, and interestingly, these changes in rank 
A
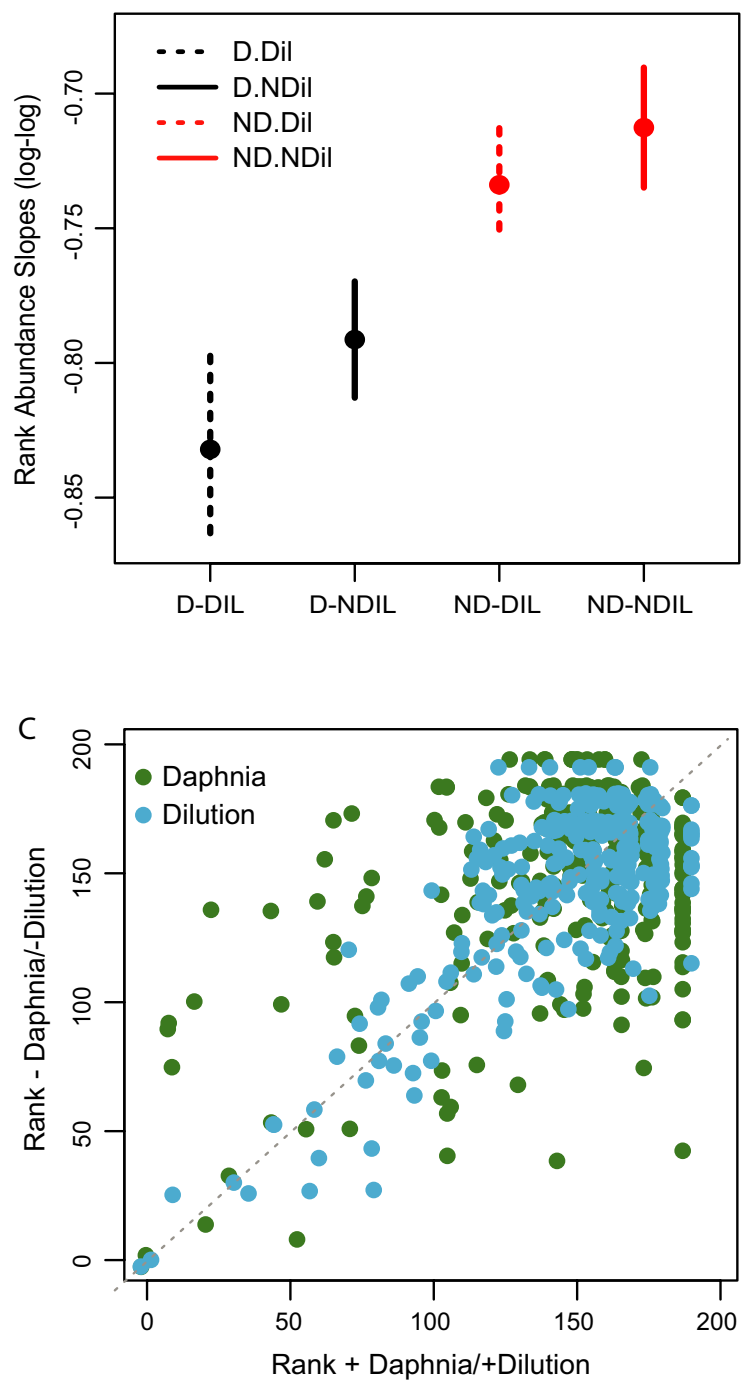

B
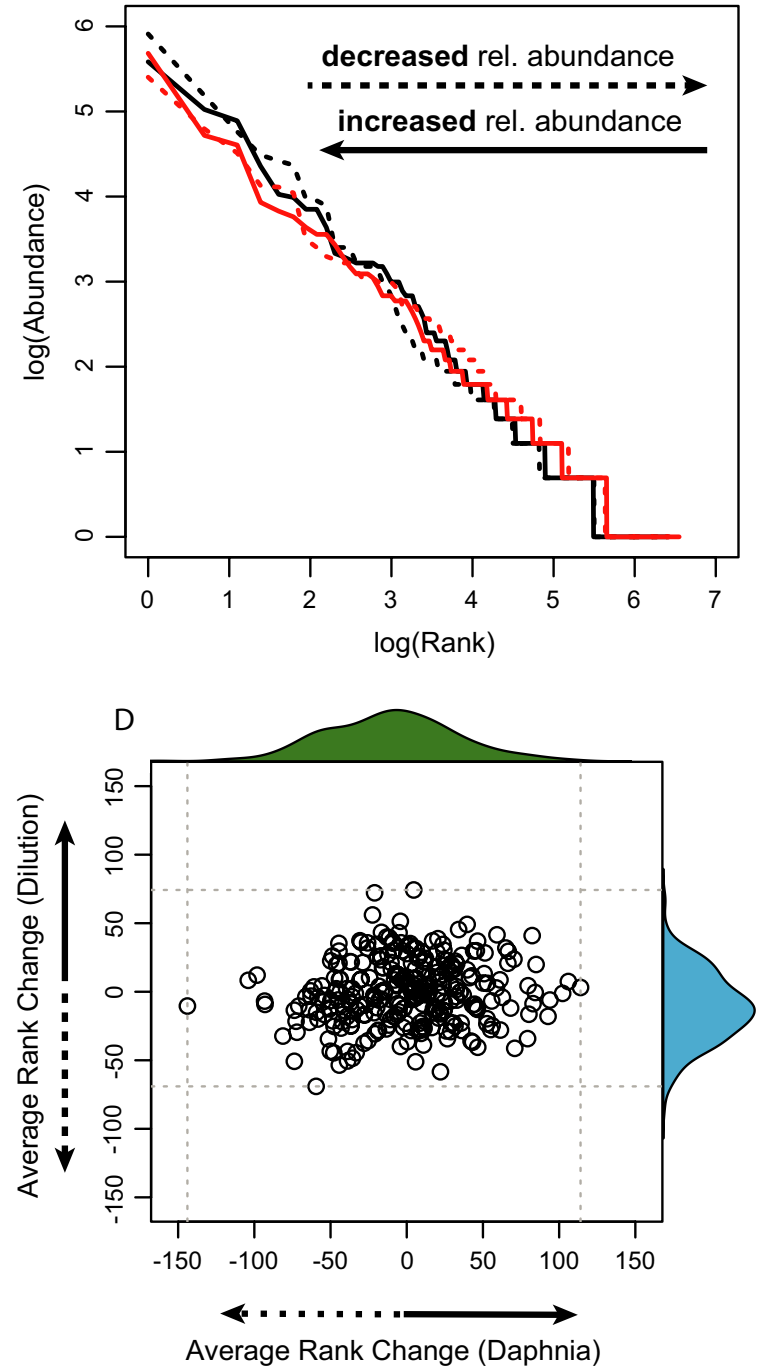

FIG. 5. Rank Abundance plots. (A) Changes in rank abundance slopes (log-log) with treatment (treatment codes: see Fig. 1), indicating mean and standard error. (B) Average rank abundance plot of the four treatments. (C) Rank plot of individual OTUs using the Top 300 OTUs across the rarefied dataset. $x$-axis: Average rank with Daphnia/Dilution, $y$-axis: average rank without Daphnial Dilution. Green dots: Daphnia contrast, blue dots: Dilution contrast. (D) Average rank change of individual OTUs of the Top 300 OTUs as an effect of Daphnia treatment ( $x$-axis) and Dilution treatment ( $y$-axis). Each dot shows the rank change of an individual OTU, histograms show the distribution of the points as an effect of treatment. (Color figure can be viewed at wileyonlinelibrary.com.)

among species showed significant phylogenetic signal (Fig. 6; Appendix S1: Table S3). Previous studies have used phylogenies to explore how species relatedness can predict responses to environmental change or stress, even when little is known about the tolerance traits of different species (Helmus et al. 2010). For bacteria in multispecies communities, where trait information is limited, we propose that phylogenies can be useful for testing whether closely related species share similar responses to environmental changes. Indeed, we found that OTUs with higher sequence similarity (i.e., higher relatedness) responded in similar ways to Daphnia grazing. We speculate this could result from major classes of bacteria sharing similar traits (e.g., size, motility) associated with grazing resistance (Jürgens et al. 1999, Pernthaler 2005). Testing this further would require additional quantification of bacterial traits and their distributions on a phylogeny.

In our analysis of ecosystem responses, we found an interactive effect of dilution and Daphnia on respiration rates, but no treatment effects on phosphatase activity (Table 2). The lack of effect on phosphatase activity is not entirely surprising because previous work has found that such generalized enzyme activities are not very sensitive to compositional changes in bacterial communities (Comte and del Giorgio 2010). The interactive effect of Daphnia and dilution on respiration rates 

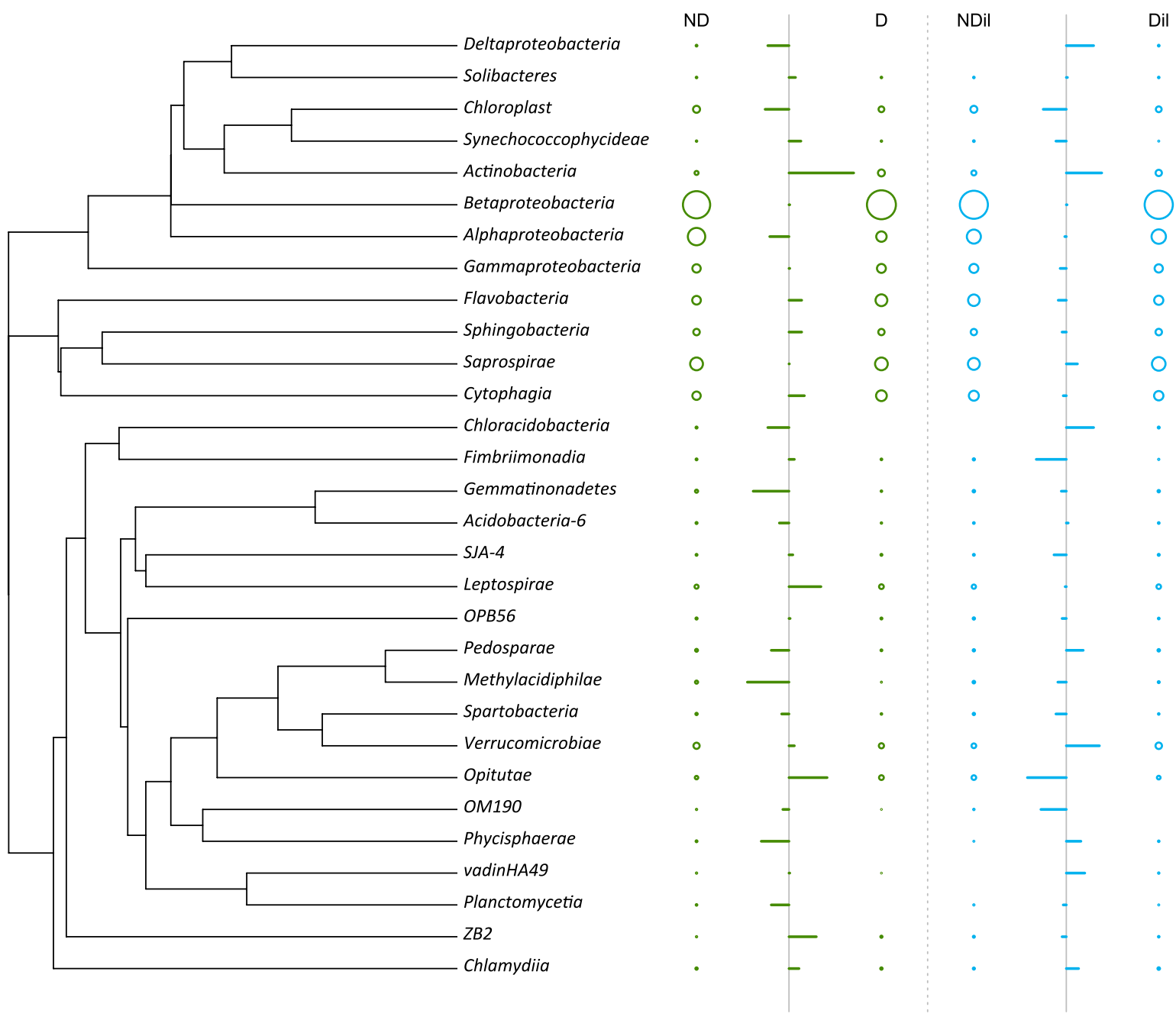

FIG. 6. Phylogenetic tree of the Top 300 OTUs aggregated to Class level, indicating average abundance and rank change of the Daphnia (green) and Dilution contrast (blue). Green dots: Average abundance of the phylogenetic groups in metacommunities without Daphnia (ND) and with Daphnia (D). Green lines: rank change of the phylogenetic groups between D/ND metacommunities. Blue dots and lines: Average abundance and rank change in the undiluted (NDil) as well as the diluted (Dil) metacommunities. (Color figure can be viewed at wileyonlinelibrary.com.)

(Appendix S1: Figure S2) of metacommunities is difficult to interpret without additional experiments. We have compelling evidence that Daphnia affected the composition of bacterial communities (Fig. 4), and that major classes of bacteria are influenced by a combination of both Daphnia and dilution (Table 2). For example, Betaproteobacteria are known to be fastgrowing (Simek et al.2006), they were the most abundant group of bacteria $(39 \%)$ in all metacommunities, and they significantly increased in their relative abundance in the presence of Daphnia. It is possible that Daphnia caused a compositional shift toward smaller and faster growing bacterial taxa, and this impacted community-wide rates of respiration.

Overall, our results contribute to growing evidence that consumers can strongly affect the composition of the bacteria community, and offer a possible explanation for the pervasive effects of consumers on biogeochemical processes (Atwood et al. 2013, Schmitz et al. 2014). As predicted (Fig. 1), we found that our manipulation of Daphnia significantly affected the relative abundance of both dominant and rare species, culminating in a higher variance in the distribution of rank changes (Fig. 5D) and a steeper rank-abundance relationship (Fig. 5B). Using NGS methods revealed that closely related species share similar response to the presence of Daphnia (Fig. 6), and that across the entire community (Fig. 5), these effects of Daphnia were much stronger than the million fold reduction in the initial bacterial inoculum (size fraction: $0.2-5 \mu \mathrm{m}$ ) to the ecosystems. In light of these results, more work is needed to identify the mechanisms underlying how Daphnia in particular, and consumers in general, can affect biogeochemical changes in spatially structured ecosystems 
through effects on microbial diversity and community structure (Battin et al. 2003, Bell et al. 2005, Besemer et al. 2009, Comte and del Giorgio 2010, Atwood et al. 2013).

\section{ACKNowledgments}

We thank Dany Steiner, Justin Boucher, and Doris Hohmann for help with setting up and sampling of the mesocosm experiment, Regula Illi for counting phytoplankton abundances, and the GDC Zurich for assistance with Illumina library preparation and sequencing. Furthermore, we acknowledge the financial support of the SNF grant 31003A-125006: "Food-web and ecosystem responses to global change".

\section{Statement of Authorship}

JB and BM designed the study. JB conducted the mesocosm experiment, collected data and performed the sequencing. JB and $\mathrm{BM}$ performed the analysis. JB wrote the first draft of the manuscript and $\mathrm{BM}$ revised it.

\section{Literature Cited}

Atwood, T. B., E. Hammill, H. S. Greig, P. Kratina, J. B. Shurin, D. S. Srivastava, and J. S. Richardson. 2013. Predator-induced reduction of freshwater carbon dioxide emissions. Nature Geoscience 6:191-194.

Battin, T. J., L. A. Kaplan, J. Denis Newbold, and C. M. E. Hansen. 2003. Contributions of microbial biofilms to ecosystem processes in stream mesocosms. Nature 426:439-442.

Bell, T., J. A. Newman, B. W. Silverman, S. L. Turner, and A. K. Lilley. 2005. The contribution of species richness and composition to bacterial services. Nature 436:1157-1160.

Berga, M., O. Ostman, E. S. Lindström, and S. Langenheder. 2014. Combined effects of zooplankton grazing and dispersal on the diversity and assembly mechanisms of bacterial metacommunities. Environmental Microbiology 7:2275-2287.

Besemer, K., G. Singer, I. Hödl, and T. J. Battin. 2009. Bacterial community composition of stream biofilms in spatially variable-flow environments. Applied and Environmental Microbiology 75:7189-7195.

Birtel, J., J.-C. Walser, S. Pichon, H. Bürgmann, and B. Matthews. 2015. Estimating bacterial diversity for ecological studies: methods, metrics, and assumptions. PLoS ONE 10:e0125356.

Böing, W. J., A. Wagner, H. Voigt, T. Deppe and J. Benndorf. 1998. Phytoplankton responses to grazing by Daphnia galeata in the biomanipulated Bautzen reservoir - Springer. Hydrobiologia 1:101-114.

Cadotte, M. W., B. J. Cardinale, and T. H. Oakley. 2008. Evolutionary history and the effect of biodiversity on plant productivity. Proceedings of the National Academy of Sciences 105:17012-17017.

Chase, J. M. 2003. Community assembly: When should history matter? Oecologia 136:489-498.

Chase, J. M., E. G. Biro, W. A. Ryberg, and K. G. Smith. 2009. Predators temper the relative importance of stochastic processes in the assembly of prey metacommunities. Ecology Letters 12:1210-1218.

Comte, J., and P. A. del Giorgio. 2010. Linking the patterns of change in composition and function in bacterioplankton successions along environmental gradients. Ecology 91:1466-1476.

Cram, J., A. Parada, and J. Fuhrman. 2016. Dilution reveals how viral lysis and grazing shape microbial communities. Limnology and Oceanography 61:889-905.
Declerck, S. A. J., C. Winter, J. B. Shurin, C. A. Suttle, and B. Matthews. 2012. Effects of patch connectivity and heterogeneity on metacommunity structure of planktonic bacteria and viruses. ISME Journal 7:533-542.

Duffy, J. 2002. Biodiversity and ecosystem function: the consumer connection. Oikos 99:201-219.

Duffy, J., B. J. Cardinale, K. France, P. McIntyre, E. Thébault, and M. Loreau. 2007. The functional role of biodiversity in ecosystems: incorporating trophic complexity. Ecology Letters 10:522-538.

Elser, J. J., and J. Urabe. 1999. The stoichiometry of consumerdriven nutrient recycling: theory, observations, and consequences. Ecology 80:735-751.

Falkowski, P. G., T. Fenchel, and E. F. DeLong. 2008. The microbial engines that drive earth's biogeochemical cycles. Science 320:1034-1039.

Fidell, L. S., and B. G. Tabachnick. 2006. Using multivariate statistics. Harper and Row, New York.

Frossard, A., L. Gerull, M. Mutz, and M. O. Gessner. 2011. Disconnect of microbial structure and function: enzyme activities and bacterial communities in nascent stream corridors. ISME Journal 6:680-691.

Fukami, T. 2015. Historical contingency in community assembly: integrating niches, species pools, and priority effects. Annual Review of Ecology, Evolution, and Systematics 46:1-23.

German, D. P., M. N. Weintraub, A. S. Grandy, C. L. Lauber, Z. L. Rinkes, and S. D. Allison. 2011. Optimization of hydrolytic and oxidative enzyme methods for ecosystem studies. Soil Biology and Biochemistry 43:1387-1397.

Giraldo, D., P. Ortolano, and A. Vieira. 2007. Bacteria-algae association in batch cultures of phytoplankton from a tropical reservoir: the significance of algal carbohydrates. Freshwater Biology 52:1281-1289.

Gophen, M., and W. Geller. 1984. Filter mesh size and food particle uptake by Daphnia. Oecologia 64:408-412.

Gravel, D., F. Guichard, M. Loreau, and N. Mouquet. 2010. Source and sink dynamics in meta ecosystems. Ecology 91:2172-2184.

Hahn, M. W., and M. G. Hoefle. 2001. Grazing of protozoa and its effect on populations of aquatic bacteria. FEMS Microbiology Ecology 35:113-121.

Hartmann, H. J., and D. D. Kunkel. 1991. Mechanisms of food selection in Daphnia. Hydrobiologia 225:129-154.

Harvey, H. W., L. H. N. Cooper, M. V. Lebour, and F. S. Russell. 1935. Plankton production and its control. Journal of the Marine Biological Association UK 20:407-442.

Helmus, M. R., W. B. Keller, M. J. Paterson, N. D. Yan, C. H. Cannon, and J. A. Rusak. 2010. Communities contain closely related species during ecosystem disturbance. Ecology Letters 13:162-174.

Hillebrand, H., L. Gamfeldt, P. R. Jonsson, and B. Matthiessen. 2009. Consumer diversity indirectly changes prey nutrient content. Marine Ecology Progress Series 380:33-41.

Jack, J. D., and J. J. Gilbert. 1994. Effects of Daphnia on microzooplankton communities. Journal of Plankton Research 16:1499-1512.

Jones, C., J. Lawton, and M. Shachak. 1997. Positive and negative effects of organisms as physical ecosystem engineers. Ecology 78:1946-1957.

Jones, S., R. J. Newton, and K. D. McMahon. 2008. Potential for atmospheric deposition of bacteria to influence bacterioplankton communities. FEMS Microbiology Ecology 64: 388-394.

Jürgens, K. 1994. Impact of Daphnia on planktonic microbial food webs a review. Marine Microbial Food Webs 8: 295-324. 
Jürgens, K., and C. Matz. 2002. Predation as a shaping force for the phenotypic and genotypic composition of planktonic bacteria. Antonie van Leeuwenhoek 81:413-434.

Jürgens, K., H. Arndt, and K. O. Rothhaupt. 1994. Zooplankton-mediated changes of bacterial community structure. Microbiology Ecology 27:27-42.

Jürgens, K., J. Pernthaler, S. Schalla, and R. Amann. 1999. Morphological and compositional changes in a planktonic bacterial community in response to enhanced protozoan grazing. Applied and Environmental Microbiology 65:1241-1250.

Kamjunke, N., and R. Zehrer. 1999. Direct and indirect effects of strong grazing by Daphnia galeata on bacterial production in an enclosure experiment. Journal of Plankton Research 21:1175-1182.

Kuczynski, J., J. Stombaugh, W. A. Walters, A. González, J. G. Caporaso, and R. Knight. 2011. Using QIIME to analyze 16S rRNA gene sequences from microbial communities. Current Protocols in Bioinformatics Chapter 10:Unit 10.7.

Lampert, W. 1978. Releaser of dissolved organic carbon by grazing zooplankton. Limnology and Oceanography 23: 831-834.

Langenheder, S., and K. Jürgens. 2001. Regulation of bacterial biomass and community structure by metazoan and protozoan predation. Limnology and Oceanography 46:121-134.

Llirós, M., E. O. Casamayor, and C. Borrego. 2008. High archaeal richness in the water column of a freshwater sulfurous karstic lake along an interannual study. FEMS Microbiology Ecology 66:331-342.

Lozupone, C., and R. Knight. 2005. UniFrac: A new phylogenetic method for comparing microbial communities. Applied and Environmental Microbiology 71:8228-8235.

Lundin, D., I. Severin, J. B. Logue, O. Ostman, A. F. Andersson and E. Lindstrom. 2012. Which sequencing depth is sufficient to describe patterns in bacterial alpha? and beta? diversity? Environmental Microbiology Reports 4:367-372.

Mazumder, A., and D. R. S. Lean. 1994. Consumer-dependent responses of lake ecosystems to nutrient loading. Journal of Plankton Research 16:1567-1580.

McIntyre, P. B., A. S. Flecker, M. J. Vanni, J. M. Hood, B. W. Taylor, and S. A. Thomas. 2008. Fish distributions and nutrient cycling in streams: Can fish create biogeochemical hotspots? Ecology 89:2335-2346.

Mouquet, N., D. Gravel, F. Massol, and V. Calcagno. 2013. Extending the concept of keystone species to communities and ecosystems. Ecology Letters 16:1-8.

Ngai, J. T., and D. S. Srivastava. 2006. Predators accelerate nutrient cycling in a bromeliad ecosystem. Science 314:963-963.

Nizzetto, L., R. Gioia, J. Li, K. Borga, F. Pomati, R. Bettinetti, J. Dachs, and K. C. Jones. 2012. Biological pump control of the fate and distribution of hydrophobic organic pollutants in water and plankton. Environmental Science and Technology 46:3204-3211.

Paine, R. T. 1966. Food web complexity and species diversity. The American Naturalist 100:65-75.

Pernthaler, J. 2005. Predation on prokaryotes in the water column and its ecological implications. Nature Reviews Microbiology 3:537-546.

Pomati, F., N. J. B. Kraft, T. Posch, B. Eugster, J. Jokela, and B. W. Ibelings. 2013. Individual cell based traits obtained by scanning flow-cytometry show selection by biotic and abiotic environmental factors during a phytoplankton spring bloom. PLoS ONE 8:e71677.

Prest, E. I., F. Hammes, S. Kotzsch, M. C. M. van Loosdrecht, and J. S. Vrouwenvelder. 2013. Monitoring microbiological changes in drinking water systems using a fast and reproducible flow cytometric method. Water Research 47:7131-7142.

Salcher, M. M., J. Pernthaler, and T. Posch. 2010. Spatiotemporal distribution and activity patterns of bacteria from three phylogenetic groups in an oligomesotrophic lake. Limnology and Oceanography 55:846-856.

Sarnelle, O. 2005. Daphnia as keystone predators: effects on phytoplankton diversity and grazing resistance. Journal of Plankton Research 27:1229-1238.

Sarnelle, O. 2007. Initial conditions mediate the interaction between Daphnia and bloom-forming Cyanobacteria. Limnology and Oceanography 52:2120-2127.

Schindler, D. E. 1997. Influence of food web structure on carbon exchange between lakes and the atmosphere. Science 277:248-251.

Schmitz, O., P. A. Hambäck, and A. P. Beckerman. 2000. Trophic cascades in terrestrial systems: A review of the effects of carnivore removals on plants. The American Naturalist 155:141-153.

Schmitz, O. J., P. A. Raymond, J. A. Estes, W. A. Kurz, G. W. Holtgrieve, M. E. Ritchie, D. E. Schindler, A. C. Spivak, R. W. Wilson, and M. A. Bradford. 2014. Animating the carbon cycle. Ecosystems 17:344-359.

Sherr, E., and B. Sherr. 2002. Significance of predation by protists in aquatic microbial food webs. Antonie van Leeuwenhoek 81:293-308.

Shurin, J. B., E. T. Borer, E. W. Seabloom, K. Anderson, C. A. Blanchette, B. Broitman, S. D. Cooper, and B. S. Halpern. 2002. A cross-ecosystem comparison of the strength of trophic cascades. Ecology Letters 5:785-791.

Simek, K., K. Horňák, J. Jezbera, J. Nedoma, J. Vrba, V. Straškrábová, M. Macek, J. R. Dolan, and M. W. Hahn. 2006. Maximum growth rates and possible life strategies of different bacterio plankton groups in relation to phosphorus availability in a freshwater reservoir. Environmental Microbiology 8:1613-1624.

Sinsabaugh, R. L., et al. 2008. Stoichiometry of soil enzyme activity at global scale. Ecology Letters 11:1252-1264.

Sterner, R. 1986. Herbivores' direct and indirect effects on algal populations. Science 231:605-607.

Vellend, M. 2010. Conceptual synthesis in community ecology. The Quarterly Review of Biology 85:183-206.

Verreydt, D., L. De Meester, E. Decaestecker, M.-J. Villena, K. Van der Gucht, P. Vannormelingen, W. Vyverman, and S. A. J. Declerck. 2012. Dispersal-mediated trophic interactions can generate apparent patterns of dispersal limitation in aquatic metacommunities. Ecology Letters 15:218-226.

Wickham, S. A. 1998. The direct and indirect impact of Daphnia and Cyclops on a freshwater microbial food web. Journal of Plankton Research 20:739-755.

Zöllner, E., B. Santer, M. Boersma, H.-G. Hoppe, and K. Jürgens. 2003. Cascading predation effects of Daphnia and copepods on microbial food web components. Freshwater Biology 48:2174-2193.

\section{SUPPORTING INFORMATION}

Additional supporting information may be found in the online version of this article at http://onlinelibrary.wiley.com/ doi/10.1002/ecy.1612/suppinfo 